\title{
Transient stability analysis of low frequency railway grids
}

\author{
J. Laury, M. H. J. Bollen \& L. Abrahamsson \\ Luleå University of Technology, Sweden
}

\begin{abstract}
This paper investigates the replacement of Rotary Frequency Converters (RFCs) with Static Frequency Converters (SFCs) in the Swedish synchronoussynchronous Railway Power Supply System (RPSS) operating at $16 \frac{2}{3} \mathrm{~Hz}$. There is a need to investigate how such a system behaves when RFCs are partly replaced with SFCs, as the SFCs do not have any physical inertia.

Most of the transient stability studies published for synchronous-synchronous RPSS address the behaviour of a single RFC or SFC against an infinite bus. However, there are very few studies investigating a system with several RFCs, SFCs or a mix of both in the same converter station. This paper presents the results of a transient stability study with both RFCs and SFCs. The investigated cases consist of faults at different locations, and present the results when an RFC is replaced with an SFC in a converter station.

Keywords: rotary frequency converters, static frequency converters, $16 \frac{2}{3} \mathrm{~Hz} A C$ railways, transient stability.
\end{abstract}

\section{Introduction}

In Sweden, the Railway Power Supply System (RPSS) is operated at $16 \frac{2}{3} \mathrm{~Hz}$ and fed from the $50 \mathrm{~Hz}$ public grid through converter stations. The RPSS does not have any power generation; all electrical power is obtained from the public grid. A converter station consists of one or more Rotary Frequency Converters (RFCs) and Static Frequency Converters (SFCs).

The RFC consists of a three phase synchronous motor with the pole number $p_{\text {motor }}$ and single phase synchronous generator with the pole number $p_{\text {generator }}$, mounted on the same mechanical shaft. The active power that the loads require in the traction grid is transferred from the motor via the shaft to the generators. 
The electrical frequency is given by (1) according [1,2]. The RFC can be overloaded for a limited time, and has the possibility to handle reverse power flow. However, RFCs have long start up times and the phasing-in procedure can be complicated [3].

$$
\begin{aligned}
\text { Motor: } f_{50 \mathrm{~Hz}} & =\frac{p_{\text {motor }}}{2} f_{\text {mech }} \\
\text { Generator: } f_{16 \frac{2}{3} \mathrm{~Hz}} & =\frac{p_{\text {generator }}}{2} f_{\text {mech }}
\end{aligned}
$$

The SFC is a three phase rectifier and a single phase inverter with a common DC link or a high power cycloconverter. The SFC is controlled to mimic the behaviour of an RFC in steady state so they can be easily installed and operated in combination with existing RFCs. However, the SFC cannot be overload in the same way as the RFC and some of the SFCs cannot cope with reverse power flows.

There are limited published studies on transient stability of the low frequency RPSS compared to the large number of studies on this for the $50 \mathrm{~Hz}$ grid; further, most of those studies focus on single machine infinite bus system. Reference [4] investigates the stability of the RPSS with a parallel $132 \mathrm{kV}$ single phase line of $16 \frac{2}{3} \mathrm{~Hz}$ i.e. a centralized system.

The system described in [4] has been subjected to faults in the $132 \mathrm{kV}$ supply line and to regenerative braking. It was concluded that a converter station could maintain stability for the fault clearing times that are normal in traction systems. The critical clearing time is the time available to clear the fault before the system becomes unstable.

Reference [5] provides a general description of an RFC. It also describes the transient stability of parallel operation of several RFCs in a converter station, and studies the stability of the RFC when a train is in regenerative braking.

However, neither study considers the behaviour of a system with multiple converter stations. Therefore, there is a need for knowledge to study the behaviour of the converters in several stations during a large disturbance. These studies are essential for setting requirements on the protection and they provide essential insight in the stability of the system.

This paper presents a transient stability study of what happens when an RFC are replaced with an SFC. A simplified dynamical model of the SFC is used, which is based on the research presented in [6-8]. In the model used the is SFC described as an equivalent single phase synchronous generator. For simplicity of the studies done, the RFC motor is seen as a special kind of turbine seen from the RFC generator based on the ideas presented in [4].

With the proposed models, the converters are represented as a first order model of a synchronous machine $[9,10]$. Simulations are performed in Matlab, were the results presented consist of the power from the converter stations and units. 


\section{Models}

\subsection{Steady state model}

In steady state the RFC and SFC are assumed to behave identically, as was also assumed in [11]. Because the low frequency AC traction grid is synchronously connected to the public grid, the voltage angle at the terminals of the converters will be one third of the angle of the $50 \mathrm{~Hz}$ grid it is connected to. The steady state model used in the study originates from $[11,12]$ and describes the relationship between the $50 \mathrm{~Hz}$ grid and $16 \frac{2}{3} \mathrm{~Hz}$ grid. See equations (2) through (5); Table 1 explains the variables used.

$$
\begin{aligned}
U^{g} & =16.5-\frac{Q_{G}}{\# c o n v \cdot k_{q}} \\
\theta^{0} & =\theta^{50}-\frac{1}{3} \cdot \arctan \frac{X_{50} \cdot P_{G}}{\left(U_{m}\right)^{2}+X_{50} \cdot Q_{50}} \\
\psi & =-\frac{1}{3} \cdot \arctan \frac{X_{q}^{m} \cdot \frac{P_{G}}{\#_{c o n v}}}{\left(U_{m}\right)^{2}+X_{q}^{m} \cdot \frac{Q_{50}}{\#_{c o n v}}}-\arctan \frac{X_{q}^{g} \cdot \frac{P_{G}}{\#_{c o n v}}}{\left(U_{g}\right)^{2}+X_{q}^{g} \cdot \frac{Q_{G}}{\#_{c o n v}}} \\
\theta & =\theta^{0}+\psi\left(P_{G}, Q_{G}, U\right)
\end{aligned}
$$

In a converter station the reactive power and active power injected to the catenary are assumed to be divided over the converters installed, by ratio of their rating. The voltage will drop with increased reactive power as described by (2) from the reference voltage of $16.5 \mathrm{kV}$. Equation (4) describes the single phase terminal voltage shift, when the converter station is unloaded, and (5) describes the single phase voltage angle at the generator side $[12,13]$.

\subsection{Dynamical models}

\subsubsection{RFC dynamic model}

The RFC consists of a motor and a generator mounted on the same mechanical shaft; the motion of these machines is described by Newton's second law, c.f. equations (6-7)

$$
\begin{aligned}
& M^{m} \ddot{\delta}_{M}=P_{50 \mathrm{~Hz}}-P_{m} \\
& M^{g} \ddot{\delta}_{G}=P_{m}-P_{16 \frac{2}{3} \mathrm{~Hz}}
\end{aligned}
$$

The shaft is assumed to be stiff, and the RFC is assumed to have no losses. The generator and motor share the same mechanical angle. A result of this is that the angle can be converter to respective electrical angle by multiplying with the number of pole pairs of either the motor or generator, see equation (1). As result of this, the inertia constant can be added and a inertia coefficient can be calculated. 
Table 1: Explanation of denotations of rotary converter equations.

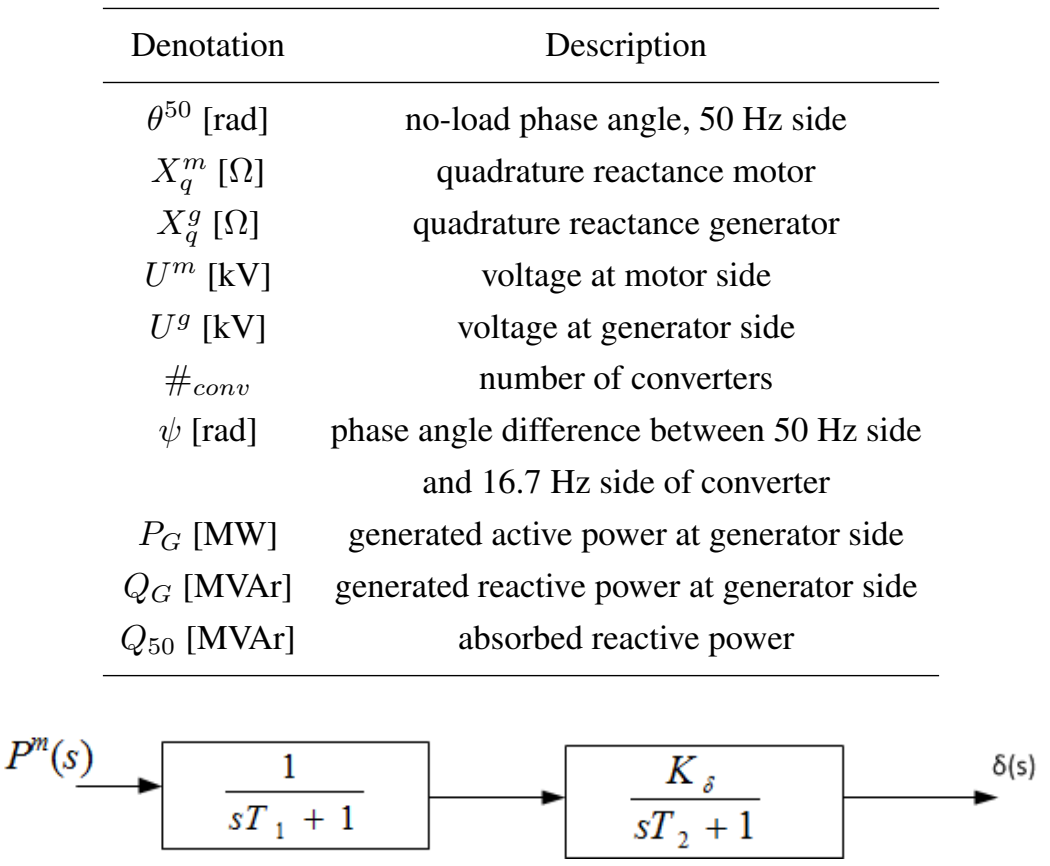

Figure 1: Block diagram of phase angle dynamics for a SFC.

The total load angle expressed in $16 \frac{2}{3} \mathrm{~Hz}$ angle is given by (8).

$$
\left(M^{m g}\right) \ddot{\delta}_{g}+D \dot{\delta}_{g}=P_{50 \mathrm{~Hz}}-P_{16 \frac{2}{3} \mathrm{~Hz}}
$$

The subscripts $m$ and $g$ stand for motor and generator, respectively. As seen in (8), the total mass is placed on the RFC generator. A damping constant $D$ is added to equation (8) which represent the damping of the machines.

\subsubsection{SFC dynamic model}

In this paper the SFC is modelled as a controllable voltage source, where active power can be controlled independently of reactive power [11]. The SFC is modelled as an equivalent generator, as seen from the railway grid. The active power output is controlled through droop control. The angle compounding is dependent on the filter that is used to filter the instantaneous power to obtain an average power [14]. The angle compounding is represented by two first order transfer functions, c.f. Figure 1.

The transfer function describing the angle compounding is expressed by equation (9), where $T_{1}$ and $T_{2}$ are time constants describing the time delay of 
the filter and the time delay of the converter.

$$
\delta(s)=K_{\delta} \frac{P_{e l}^{m}(s)}{\left(1+\left(T_{1}+T_{2}\right) s+T_{1} T_{2} s^{2}\right)}
$$

where $K_{1}=T_{1}+T_{2}$ and $K_{2}=T_{1} T_{2}$. Equation (9) is then expressed in time domain form according to equation (10)

$$
\frac{K_{2}}{K_{\delta}} \ddot{\delta}(t)+\frac{K_{1}}{K_{\delta}} \dot{\delta}(t)=P_{r e f}-P_{e l}^{m}
$$

The angle compounding of the SFC is described as a second order differential equation, resembling the classical swing equation.

The SFC cannot be overloaded, not even for a short time, due to the power electronic devices that it contains. The SFC output current is therefore limited. This is done by an algorithm that checks if the current magnitude is above a threshold. If the current is above the threshold, the magnitude of the current is reduced. A new equivalent voltage and a new angle for the inverter are calculated to match the maximum current.

\subsection{Model of system}

As both the RFC and SFC are described with the classical model of a generator, a multimachine transient stability approach according to reference [10] is used. The trains are described as constant impedances, and the movement of the trains is not considered. The justification why the train movement is not considered is that the trains will have travelled only $625 \mathrm{~m}$ at a velocity of $150 \mathrm{~km} / \mathrm{h}$ during the studied time; thus its influence on the system can be neglected. Furthermore it is assumed that RFCs or SFCs of the same type swing together and can therefore be considered as one unit. It is also assumed that the mechanical angle coincides with the load angle of the RFC generator.

\section{Case studies and results}

\subsection{Cases}

The studied system consists of two converter stations and two overhead contact lines that connect the converter stations. Both converter stations have two converters. The RFC rating is $10 \mathrm{MVA}$, whereas an SFC has a rating of $15 \mathrm{MVA}$. The distance between the converter stations is $100 \mathrm{~km}$. Trains are positioned $25 \mathrm{~km}$ from converter station 1 and converter station 2 . The consumption of each train is $10 \mathrm{MW}$ with a power factor equal to 0.99 . The distance between the trains is $50 \mathrm{~km}$, see Figure 2.

In order to study the system when one of the RFCs in converter station 1 is replaced with an SFC, single phase to ground faults are applied according to the list below. 


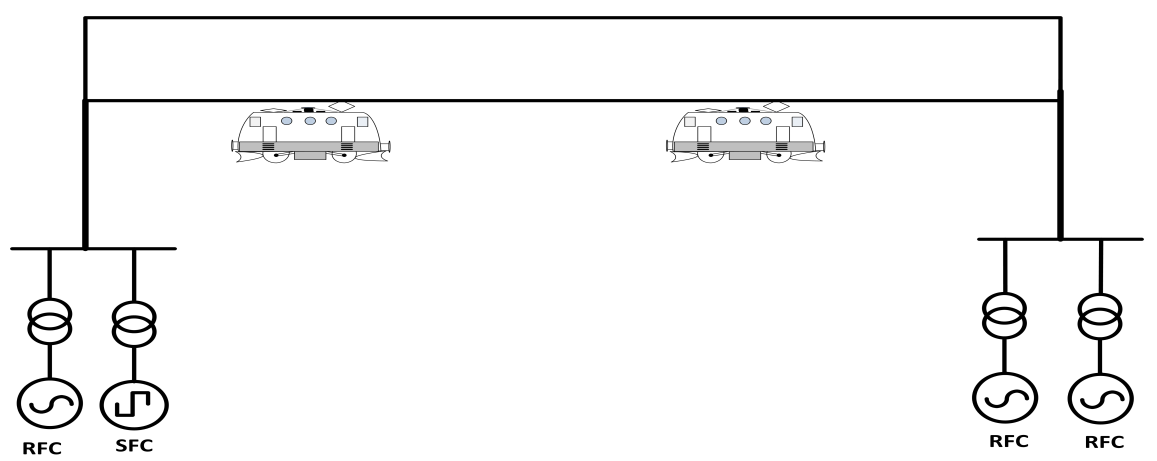

Figure 2: The system investigated.

- Case 1: Fault applied $25 \mathrm{~km}$ from converter station 1.

- Case 2: Fault applied $50 \mathrm{~km}$ from converter station 1.

- Case 3: Fault applied $75 \mathrm{~km}$ from converter station 1.

\subsection{Results}

When an RFC is replaced with an SFC in converter station 1, the consequence is converter station 1 becomes stronger than converter station 2 regarding installed power. This results that in steady state converter station 1 will deliver more power to the system.

\subsubsection{Case 1}

When there is only RFC operating in the system, and the fault is applied $25 \mathrm{~km}$ from station 1 , converter station 1 reduces its power output whereas converter station 2 increases its power output, see Figure 3 . The increase of power output from converter station 2 is because that station has to supply the majority of the increased ohmic losses during the fault. After fault clearing, the converter stations oscillate against each other.

When one of the RFCs is replaced with an SFC, the active power during the fault from station 1 decreases as the SFC enters current limitation mode, resulting that converter station 2 has to increase its power output. Power oscillations in the range of $1.1 \mathrm{~Hz}$ to $1.2 \mathrm{~Hz}$ are observed from the converter units in station 1 . There are no longer any power oscillations between the converter stations; instead oscillations occur between the SFC and the RFC in converter station 1.

\subsubsection{Case 2}

From Figure 5 it is concluded that there is no power oscillation because the two converter stations have the same impedance to the fault, and they deliver equal active power. Replacing one RFC with an SFC in converter station 1 results in that the SFC enters current limitation mode during the fault and that it therefore 


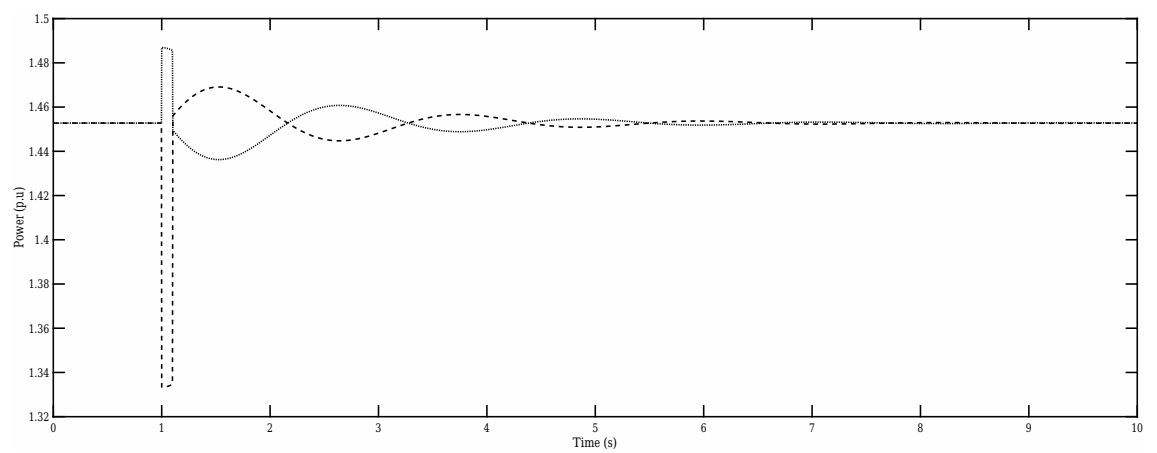

Figure 3: Case 1: Active power from converter stations - RFCs only. Dashed line - converter station 1. Dotted line - converter station 2.

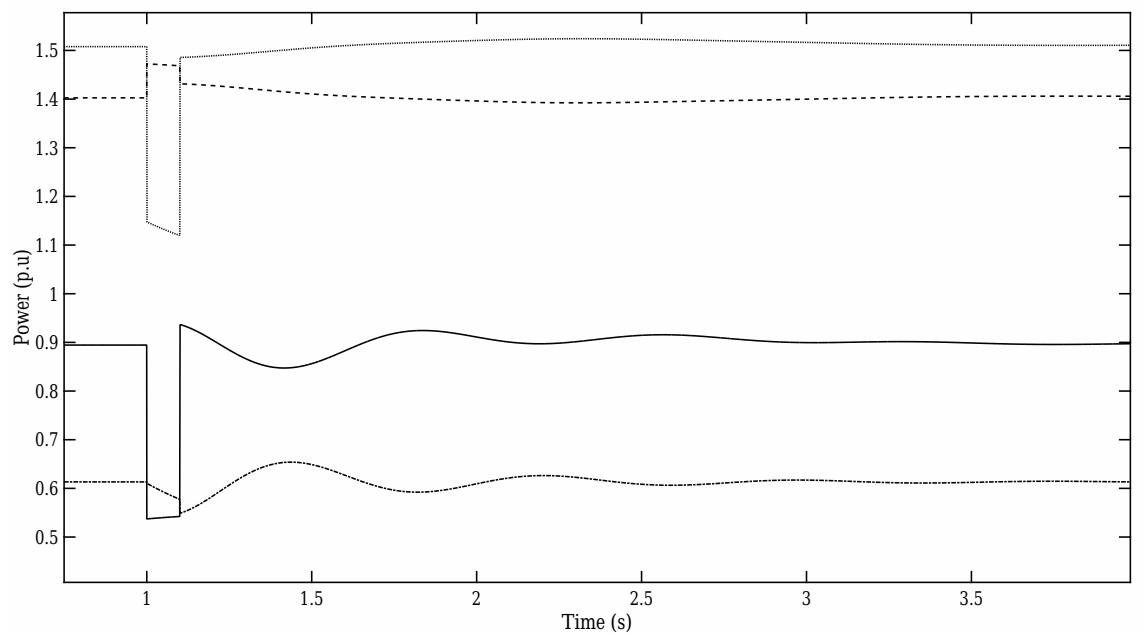

Figure 4: Case 1: Active power from converter stations and individual converters RFCs and SFC. Dashed line - converter station 1. Dotted line - converter station 2. Solid line - SFC. Dash-dotted line - RFC.

reduces its active power output. A direct consequence of this is that the total power output from converter station 1 is reduced. This in turn results in that converter station 2 increases its power output by approximately 0.05 p.u. Another result of the replacing an RFC with an SFC in converter station 1 is that power oscillations are introduced, see Figure 6.

\subsubsection{Case 3}

As show in Figure 7 the output power of converter station 2 is reduced as the fault is closer to this station that to converter station 1 . Converter station 1 and 2 


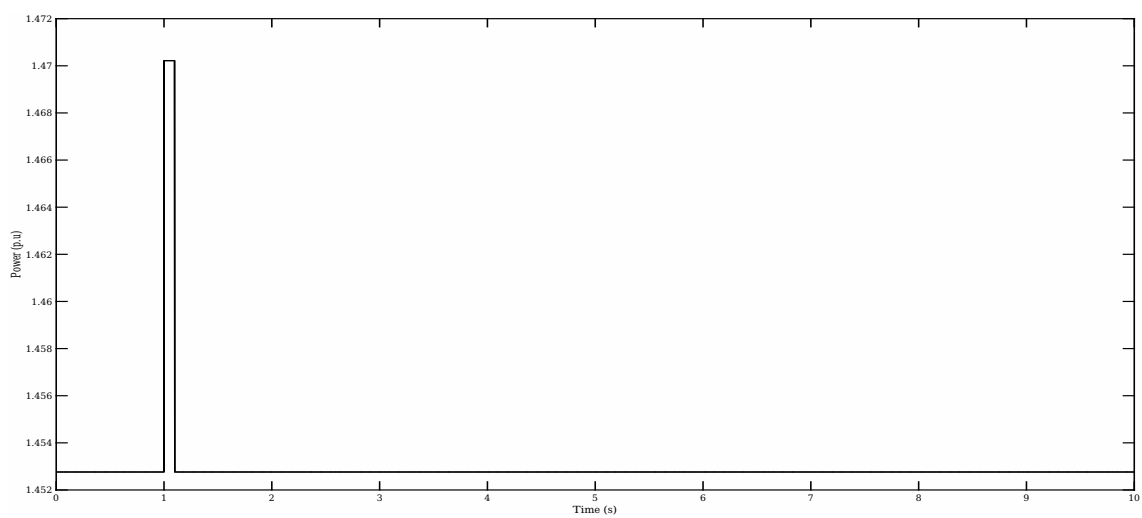

Figure 5: Case 2: Active power from converter stations - RFCs only. Dashed line - converter station 1. Dotted line - converter station 2.

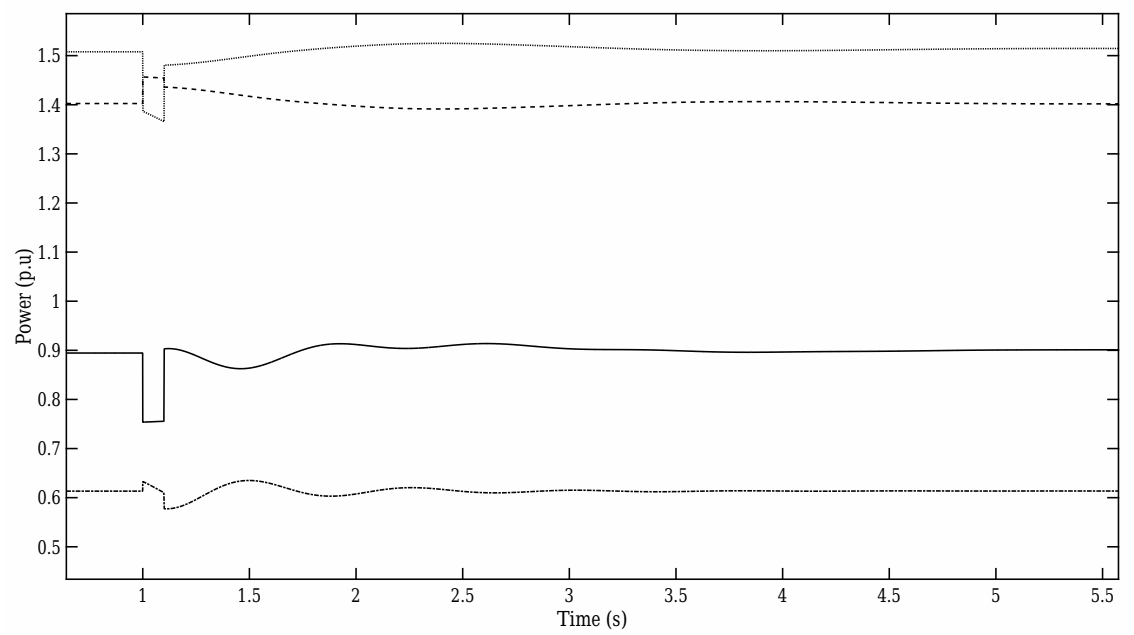

Figure 6: Case 2: Active power from converter stations and individual converters RFCs and SFC. Dashed line - converter station 1. Dotted line - converter station 2. Solid line - SFC. Dash-dotted line - RFC.

oscillate against each other with a frequency of approximately $0.5 \mathrm{~Hz}$, when only RFCs are present, see Figure 7. From Figure 8 it is concluded that when one RFC is replaced with an SFC in converter station 1, converter station 1 slightly reduces its power output during the fault as the SFC enters current limitation mode. The power oscillations after fault clearing are approximately $1.2 \mathrm{~Hz}$ for the converter units in station 1 . However, the power oscillations between the converter stations are limited. 


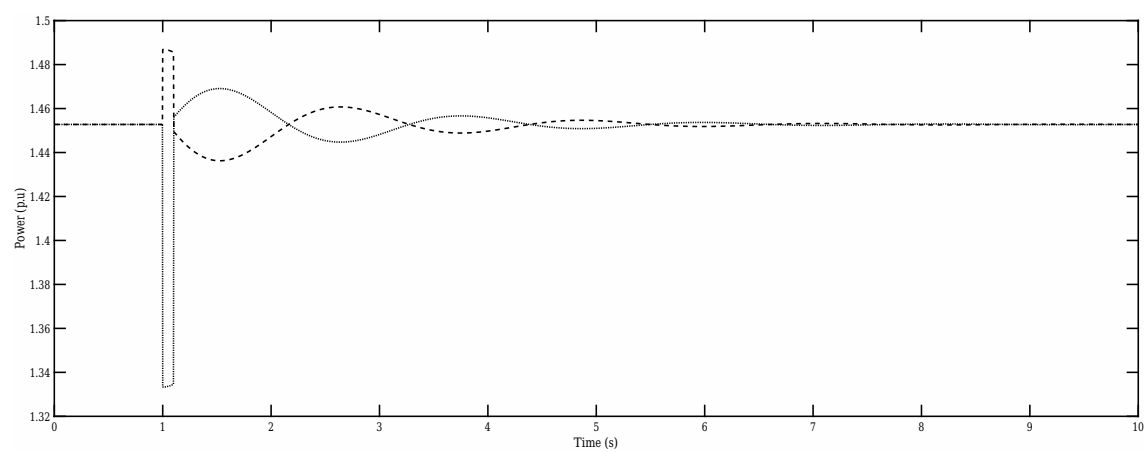

Figure 7: Case 3: Active power from converter stations - RFCs only. Dashed line - converter station 1. Dotted line - converter station 2.

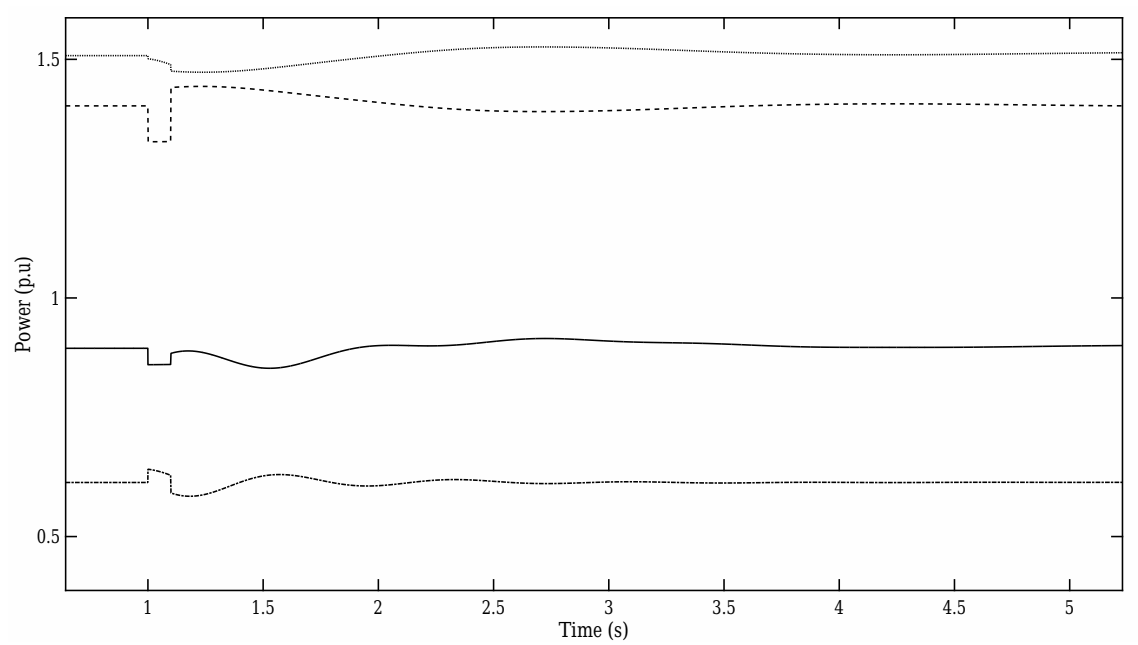

Figure 8: Case 3: Active power from converter stations and individual converters RFCs and SFC. Dashed line - converter station 1. Dotted line - converter station 2. Solid line - SFC. Dash-dotted line - RFC.

\section{Conclusions and future work}

This paper presents a transient stability study of a low frequency AC railway. The aim of the study is to find out what happens with the transient stability for the system after a fault, when an RFC is replaced with an SFC. The SFC is modelled with current limitation to investigate the impact of this on the studied system. The system has two trains consuming total $20 \mathrm{MW}$ at a power factor equal to 0.99 .

The system, where the faults were applied 25, 50 and $75 \mathrm{~km}$ from a converter station, was shown to be stable after fault clearance, assuming realistic fault- 
clearing times. Replacing a RFC with a SFC did not cause the system to lose synchronism.

The simulations show the occurrence of power oscillations between converter stations at a frequency of approximately $0.5 \mathrm{~Hz}$ when only RFCs are installed. Replacing an RFC with an SFC in a converter station reduces the power oscillations between the converter stations, but introduces power oscillations from the converter units.

Future work is needed to obtain a more detailed description of the RFCs and SFCs. Such models are needed to be able to investigate and obtain a better understanding of the converter control system and its influence on the overall stability.

\section{References}

[1] Danielsen, S., Electric Traction Power System Stability. Ph.D. thesis, Norwegian University of Science and Technology, 2010.

[2] Heising, C., Fang, J., Bartelt, R., Staudt, V. \& Steimel, A., Modelling of rotary converter in electrical railway traction power-systems for stability analysis. Electrical Systems for Aircraft, Railway and Ship Propulsion, (3), pp. 1-6, 2010.

[3] Östlund, S., Electric Railway Traction. School of Electrical Engineering, Royal Insitute of Technology: Stockholm, 2012.

[4] Olofsson, M., Undersökning av transient stabilitet $i$ matningssytem för elektrisk tågdrift. Master thesis, Kungliga Tekniska Högskolan, 1989.

[5] Schimdt, P. \& Biesenack, H., Die dezentrale Bahnenergieversorgung von 16(2/3)-Hz-Einphasen-wechselstrombahnen über Synchron-SynchronUmformer. Elektrische Bahnen, 11, pp. 178-181, 1991.

[6] D’Arco, S. \& Suul, J.A., Virtual synchronous machines Classification of implementations and analysis of equivalence to droop controllers for microgrids. 2013 IEEE Grenoble Conference, IEEE, pp. 1-7, 2013.

[7] Schiffer, J., Goldin, D., Raisch, J. \& Sezi, T., Synchronization of droopcontrolled microgrids with distributed rotational and electronic generation. 52nd IEEE Conference on Decision and Control, IEEE, pp. 2334-2339, 2013.

[8] Eitzmann, M., Paserba, J., Undrill, J., Amicarella, C., Jones, A., Khalafalla, E. \& Liverant, W., Model development and stability assessment of the Amtrak $25 \mathrm{~Hz}$ traction system from New York to Washington DC. Proceedings of the 1997 IEEE/ASME Joint Railroad Conference, IEEE, pp. 21-28, 1997.

[9] Kundur, P., Power System Stability and Control. McGraw-Hill, Inc., 1994.

[10] Saadat, H., Power System Analysis. PSA Publishing, 3rd edition, 2010.

[11] Olofsson, M., Optimal Operation of the Swedish Railway Electrical System - An application of Optimal Power Flow. Phd thesis, Royal Institute of Technology, 1996. 
[12] Abrahamsson, L., Railway Power Supply Models and Methods for Longterm Investment Analysis. Technical Report 2008:036, KTH, Electric Power Systems, 2008.

[13] Laury, J., Abrahamsson, L. \& Ostlund, S., OPF for an HVDC Feeder Solution for Railway Power Supply Systems. OPF for an HVDC Feeder Solution for Railway Power Supply Systems, WIT, p. 12, 2012.

[14] Andrade, F., Cusido, J. \& Romeral, L., Transient stability analysis of inverterinterfaced distributed generators in a microgrid system, 2011. 